\title{
DENTAL HEALTH EDUCATION FOR A COMMUNITY'S PARENTS*
}

\author{
By Shirley R. Pyke, RDH, MPH**
}

Those of you interested in technics of oral health education, that motivate action or change and can be assessed for effectiveness, are advised to read Mrs. Pyke's penetrating report.

This paper will present an approach to dental health education that the reader may consider either unique or irrelevant. The reason for this approach arises from plenty of experience as a public health dental hygienist in a large metropolitan county health department and some specialized experience as a community health educator in a federally funded program to provide health care. These experiences convince one that the only difference between dental and generalized health education is the subject matter. The basic principles of health education maintain regardless of the discipline to be promoted. As a dental hygienist gains experience in communal health education, hence, she is bound to think and speak in terms of the total person, not just that person's oral cavity.

\section{Some Ground Rules}

At this point a very few simple ground rules have to be established. All who follow sports today soon seem to learn that each one has established rules for procedure which must be accepted by all participants. As one gains experience with current health education, the more suspicious he is apt to become that the personnel of health programs have indeed been playing a game without much attention spent on the rules. The ground rules for the discussion to follow are merely three definitions. They have to be submitted, however, to make certain that the term health education will be understood clearly before it is practiced. They include health, education, and community.

Health. Beginning with health, perhaps the definition of the World Health Organization ideally is most suitable:" ". . . a state of complete physical, mental, and social well-being, not merely the absence of disease or infirmity." For today's discussion, however, one should think of health as an abstraction which may be defined in terms of the degree to which it permits or interferes with an individual's usual daily functioning.

Education. Here is a term with many definitions and they depend on the professional discipline which is defining education. All appear to agree that education is a process. ${ }^{2}$ The definition used in this discussion will be the all-encompassing, "Education is the process of development through learning-experiences."

Community. Here is another term which depends on the person who defines it. Connor's definition ${ }^{3}$ has been accepted for today's game: "A community is composed of a number of people living in a certain area, possessing a sense of group-identity, and sharing a common culture."

\footnotetext{
*Paper presented at first National Children and Youth, Dental Directors' Conference, Detroit, Michigan, May 6, 1970.

**Formerly Consultant on Community Relations and Health Education, Project Prescad, Detroit, and now Lecturer in Dental Public Health, The University of Michigan, School of Public Health, and Lecturer in Community Dentistry, School of Dentistry, Ann Arbor 48104.
} 


\section{Some Variables}

When these terms are combined in a discussion of health education for a community, each discussant faces a task of considerable dimension. Each finds that his definition depends on at least three variables which operate through cultural heritage, social mores, and economic status. They invariably alter human beliefs, attitudes, and behavior, singly or as a triad.

To get at the true issues confronting a health educator for Prescad, one finds that practically all programs are committed to the development of an improved system for delivering health care to the children of families hampered by low incomes. One finds that these families for years have been victims of the traditional system for providing health care because they never have had the money to pay the going fee per service. One learns how families have to make do with crumbs of health services, and one learns about the indignities that people often experience because they are poor or black or Spanish or migrants or Indians.

\section{Changing Health Behavior}

The specific authorization for the Children and Youth Projects, when cited, is found in Title II, Part 1, Section 205, which amended Section 532 of Title V, Part 4 of the Social Security $\mathrm{Act}^{4}$ of 1965 . As the projects were funded, their sponsors were charged to provide high quality, comprehensive, and continuing health care. It was assumed that the programs and the health personnel participating would be accepted, and in a number of geographical areas they were. In other parts of the country, particularly in large urban areas, it was found that unusual effort was demanded to bring about changes in the health behavior of the clients. For example, parents had to be convinced that staff-members cared about the children, that the children would be seen, that treatment was considered important, that preventive care was far more important to health than episodic care, that appointments once made would be honored and respected, and that the children would receive humane treatment in a setting that preserved human dignity. The best, and probably the only educational method to convince anyone that these premises can be truths, is daily demonstration.

Children and youths as patients, along with their associates, often have been educated by the system to distrust the system. Five basic, common-sense principles of procedure fortunately, can be utilized to re-educate distrustful patients. Each member of the staff can (1) become an interested listener, (2) learn to respect the patient's values instead of insisting on an educator's values, (3) include each child's parents in one's planning for health care so that participation gains cooperation, (4) intensify his own social sensitivity and awareness, and (5) behave sincerely in all of his efforts. The application of these five principles in health education is the next order of business.

An Interested Listener. Such a listener encourages conversation that frequently reveals the patient's deep concerns and true interests. This revelation provides the clue for directing motivational effort. A number of examples come to mind: (1) teenage girls frequently can be motivated to seek dental care by an explanation, in terms that they understand, of how oral hygiene enhances their appearance; (2) conversation can reveal the nondental problems which should be assigned to other members of the health team; (3) conversation with parents may reveal the variables that affect oral health behavior in a family, and (4) conversation can determine more succinctly the parent's current knowledge or oral health, its importance, and the problems experienced in obtaining care. Be reminded, too, that many patients have been educated by hard experience not to waste the operator's time with questions and have learned how pointless questions will be when answers come in ununderstandable phrases. Questions will have to be provoked and answered in simple, direct language. A truly good professional listener eventually learns to 
admit that much is not known about his patients and that much can be learned about them just by listening.

Respecting Values. In the same way that the educator develops priorities, so do poor people. The two sets of priorities may not agree, but both are established by the circumstances that have been experienced. Among the least fortunate people in the central city, health is apt to rank fourth or fifth in priority. Jobs, housing, and education are more important than one's health, and the interrelationship of health to priority frequently is completely misunderstood. Health becomes a priority when it interferes with daily functions, for example, when a toothache interferes with sleep it first becomes important. The educator hears time after time: "Why spend the money to have baby teeth filled when they fall out soon anyhow?" and "Why bother to have teeth filled when they can be pulled out and replaced by false teeth which never ache?"

A more important question now arises, "What will be the reaction of dental personnel?" "Will this type of thinking be condemned by those who understand so clearly the value of maintained oral health?" "Are such families to be dismissed for these attitudes, for broken appointments, for not caring about health, or for being too lazy to come to the clinic?" Perhaps the professional person has an obligation to try to change thinking by gaining positive understanding, and by practicing humane approaches. Little effort is required to close out a family that misses three appointments, but a serious attempt to change attitudes requires extra effort and dangles a rewarding challenge. Reminding people of appointments, arranging for transportation, and providing a baby-sitter may be a large part of the effort that is needed.

Including Parents in Planning. During excitement over improving the health of the next generation by providing the care mandated in the Project Guidelines of the program for Children and Youth, the staff-members sometimes are guilty of excluding parents from the planning for the oral health of their children. Actually, a two-fold purpose can be served by including the parent and by explaining what will be done and why. Once the parent understands why, she then will carry out dental health education for her children at home and even some of the neighbors' children. Staff-members can preach to children about the importance of avoiding candy and bubble gum, but, if an uninformed mother does the shopping, sweet snacks will get to and tempt young patients. An understanding mother usually will cooperate in substitutes for sweets, once she comprehends the reason.

Developing Sensitivity and Awareness. Dummett ${ }^{5}$ says, ". . . the poor are different and consequently react differently to situations for a variety of reasons." He continues, "The attitude of the provider, as perceived by the patient, determines that patient's attitude toward the provider and toward the service." $\mathrm{He}$ cites the teenager who reported to a medical center for a physical examination and offended the examining physician by his uncleanliness. The response of the teenager's mother was that she brought him to be examined, not smelled. The righteous attitude of the provider provoked hostility in both mother and son. Dummett cites sufficient examples to demonstrate the different attitudes which prevail among the poor and the message that he writes is clear, "health personnel have to become socially sensitive in order to comprehend these differences."

Some dentists look with disdain at children whose toothbrushing is not a routine activity supervised by parents. Had they explored the situation in the home, they might find that there was a communal toothbrush or none at all. They also might find that nobody brushes his teeth because toothpaste is too expensive, and no one has taken time to explain to the mother that a dentifrice can be compounded at home from salt and baking soda.

The question eventually arises, "What is the magic that transforms professional personnel, oriented by education and training for private practice, into functional 
partners of a team to provide health care?" The answer is, "There is none," but an internal value can be gained just as soon as a professional person learns by experience to compete for space in a community of human beings by caring about people and being concerned about their health care. It has become obvious that there is no place in projects for Children and Youth for personnel, either professional or nonprofessional, who fail to recognize an obligation to help a fellow human being on his way to a better life.

Sincerity. Many times the question confronts a dedicated health educator, "How can one expect to motivate anyone for acceptable human behavior until he thinks sincerely that the job can be accomplished?" It may be true that one accepts a particular task when he attempts to convince an invisible segment of a population that health personnel see and care. Invisible, by way of explanation, was borrowed from a consumer who appeared with a panel during the Ninety-sixth Annual Meeting of the American Public Health Association in Detroit." This voice said, "In the old clinics, the people who worked there acted as if you weren't there, and would take care of you when they got around to it. Today, we do not know the quality of care we're getting, but we are treated as people."

The staff people for project Prescad (Project No. 616), are trying to prove that a different approach to the delivery of health care will work; consequently, there is no time to waste on professional personnel who still feel that they confer honor on patients by being there to serve them. The poor, who are served, have endured too long paternalistic handouts, unkept promises, and disappointments, and they are sufficiently sophisticated now to detect this old-time behavior promptly. At any rate, PRESCAD (PREschool, SChool, and ADolescents) has begun to function in Detroit according to the five principles outlined. No staff-member will boast of total success because the activity is big. The Dental Division has just completed 17,960 patientappointments thus far for this fiscal year and, in spite of its concentrated effort, can report a rate for broken appointments reduced to seven percent only in March of this year.

\section{Working As a Team}

As a motivational specialist interested in using educational methods which are thought to be effective, the final task of this report has to be an examination of the approach of a multiple-disciplinary team for providing comprehensive health service. How well can the human elements of its components be mobilized for success? The team, be reminded, brings together professional, paraprofessional, and supportive personnel whose goal is to function harmoniously for a common cause although each member brings with him his individual expertise, his notion of his role, his self-perception, his ideas, and his attitudes. All have to be integrated in to the team's total effort. Be reminded, further, that the real quarterbacks of any team performing for Prescad now are parents.

The Delivery of Dental Services. That the unmet dental needs of the poor are overwhelming now appears to be xccepted widely. Equally well-accepted appears to be the conclusion that past experiences of the poor in attempting to meet their own dental needs have been frustrated largely by their inability to pay for services. In consequence, the poor have developed attitudes and behavior toward oral care which professional people consider unfavorable. At the same time, dentists in the past have been so immersed in the prevention and treatment of oral disease that they have shown little concern for the social ills which are not manifested in the mouth. The job ahead, as a health educator views it, is a two-fold activity: (1) educate both patients and profession to modify their attitudes and resultant behavior; and (2) develop a system for delivering services high in quality and within a humane atmosphere. 
Delivering Oral Health Education to Patients. Oral health education no longer can be accepted as the sole demain of the dental hygienist. Granted that she may possess special expertise, the responsibility must be shared by every member of the team, particularly by the dentists. Without vigorous support by all of the team the message on oral health can be crowded out by the family's problems which demand immediate resolution. The approach used may be expected to vary, hence, for each patient. An illuminated motto may help in directing effort - "Start with the patient wherever you find him; proceed at the pace he can follow."

Delivering Sensitivity and Awareness to Dentists. Modification of the attitudes and behavior of participating dentists appears easy on initial consideration. Actually, it is a highly difficult task. From his introduction to laboratory technics as a freshman dental student, the dentist appears to have been oriented to concern about teeth rather than concern about the person who has the teeth. His concern about the family of the child whom he is treating rarely has been manifested before. Earlier in this paper, the method was broken down into five facets of procedure, four of which demand experience.

Delivering High-Quality Treatment Humanely. Delivery of a high-quality treatment in a humane atmosphere appears to be the most difficult facet of a new approach, because it includes certain intangibles which seem difficult to measure, evaluate, and enforce in a public dental clinic. Such questions arise as "How is quality-care evaluated?" "Who can perform the evaluation best?" and "What stimulates the operator's continued best effort?" Probably most of the answers will have to be provided by organized dentistry, perhaps through experience with dental prepayment, but the dental health educator has an opportunity to observe and comment on the team when requested.

Already the conclusion has been stated that no time should be wasted on dental personnel who are sluggish in attainment of sensitivity and awareness. Along with their elimination should go those persons whose attitude is affected by the interrogation, "Since they are not paying for treatment, is not any kind of restorative treatment good enough?"

As a final observation, it appears that delivery of quality dental services maintains best when oral health is recognized and accepted by all as an integral part of total health. Such recognition seems to be achieved when all of the disciplines of the team talk with each other, share their concerns about patients with each other, and then work together to meet the needs of these patients.

\section{Bibliography}

1. United Nations, World Health Organization. The World Health Organization (Charter). Geneva, World Health Organization, n.d. 12p.

2. Turner, C. E. Community health educator's compendium of knowledge. Geneva, Switzerland, Press of Typo-offset, H. Studor S. A.,, c1964. 259p.

3. Connor, D. M. Understanding your community. Antigonish, Nova Scotia, Canada, The Author, c1964. 35p.

4. Public Law 89-97, 89th Congress, July 30, 1965; Social Security Amendments of 1965. Sec. 205, as amended, to read Grants for Special Maternity and Infant Care, for Projects for Health of School and Preschool Children, and for Research Projects. Section 532 (p. 69-70). Washington, Government Printing Office, 1965. 138p.

5. Dummett, C. O. Understanding the underprivileged patient. p.1-10p. (In Proceedings of the National Dental Health Conference. Chicago, American Dental Association, 1969. Discontinuous paging)

6. 96th Annual Meeting of the American Public Health Association; Detroit, November 11-15, 1968. 